\title{
Sintesis Silika Gel dari Abu Cangkang dan Serabut Kelapa Sawit Terimobilisasi Difenilkarbazon dengan Metode Sol-Gel
}

\author{
Sonia Wimarsela*1, Robert Junaidi ${ }^{2}$, Idha Silviyati ${ }^{3}$ \\ 1,2,3Program Studi Teknologi Kimia Industri, Jurusan Teknik Kimia, Politeknik Negeri Sriwijaya, \\ Indonesia \\ Email: 1soniacahayu20@gmail.com
}

\begin{abstract}
Abstrak
Abu cangkang dan serabut kelapa sawit memiliki kadar silika tinggi yang dapat digunakan sebagai bahan baku sintesis silika gel. Silika gel mempunyai situs aktif berupa gugus silanol ( $\mathrm{Si}-\mathrm{OH})$ dan siloksan (Si-O-Si) di permukaan. Dengan adanya gugus - $\mathrm{OH}$ memberikan peluang untuk memodifikasi gugus tersebut menjadi gugus lain yang lebih aktif. Tujuan dari penelitian ini yaitu untuk menghasilkan silika gel dengan nilai daya serap uap air yang lebih tinggi dan berfungsi lebih optimum sebagai adsorben. Penelitian dilakukan dengan tiga tahapan yaitu persiapan bahan baku, sintesis silika gel dan modifikasi, dan analisis silika gel. Sintesis silika gel dilakukan dengan variasi konsentrasi $\mathrm{H}_{2} \mathrm{SO}_{4} 1$ - $5 \mathrm{M}$, waktu pematangan gel 12 dan 18 jam, dan massa difenilkarbazon 0,12 dan 0,18 g. Dari hasil penelitian didapatkan kondisi optimal sintesis silika gel terimobilisasi difenilkarbazon dicapai pada konsentrasi $\mathrm{H}_{2} \mathrm{SO}_{4} 1 \mathrm{M}$, waktu pematangan gel 18 jam, dan massa difenilkarbazon $0,12 \mathrm{~g}$. Pada kondisi ini diperoleh keasaman permukaan $6,15 \mathrm{mmol} / \mathrm{g}$, luas permukaan $16,6150 \mathrm{~m}^{2} / \mathrm{g}$, kadar air $8,4 \%$, dan daya serap 10,960 $\mathrm{mg} / \mathrm{g}$.
\end{abstract}

Kata kunci: Abu Cangkang Kelapa Sawit, Abu Serabut Kelapa Sawit, Difenilkarbazon, Metode Sol-Gel, Silika Gel, Terimobilisasi.

\begin{abstract}
Shell ash and fiber palm oil have high silica content can be used as raw materials to synthesize silica gel. Silica gel has an active site in the form of silanol $(\mathrm{Si}-\mathrm{OH})$ and siloxane ( $\mathrm{Si}-\mathrm{O}$-Si) groups on the surface. The presence of the -OH group provides a broad opportunity to modify the group into another more active group. The purpose of this research is to produce silica gel with a higher water vapor absorption value and function more optimally as an adsorbent. The experiment was carried out through three stages: the preparation of raw materials, the synthesize of silica gel and modification, and the analyzing of silica gel. Silica gel was synthesized with various concentrations of $\mathrm{H}_{2} \mathrm{SO}_{4} \mathrm{l}-5 \mathrm{M}$, gel maturation time 12 and 18 hours, and diphenylcarbazone mass 0.12 and $0.18 \mathrm{~g}$. The results showed that the optimal conditions for the synthesis of diphenylcarbazone immobilized silica gel were achieved at a concentration of $1 \mathrm{M} \mathrm{H}_{2} \mathrm{SO}_{4}, 18$ hours of gel maturation, and $0.12 \mathrm{~g}$ of diphenylcarbazone mass. In this condition, the surface acidity is $6.15 \mathrm{mmol} / \mathrm{g}$, the surface area is $16.6150 \mathrm{~m}^{2} / \mathrm{g}$, the water content is $8.4 \%$, and the absorption capacity is $10.960 \mathrm{mg} / \mathrm{g}$.
\end{abstract}

Keywords: Diphenylcarbazone, Fiber Ash Palm Oil, Immobilized, Shell Ash Palm Oil, Silica Gel, Sol-Gel Method.

\section{PENDAHULUAN}

Indonesia merupakan negara yang memiliki lahan perkebunan dan industri kelapa sawit yang tersebar luas di pulau Sumatera, Kalimantan, Sulawesi dan Papua. Provinsi Sumatera Selatan tercatat sebagai wilayah yang memiliki perkebunan sawit yang luas di Indonesia, yaitu 1.215.476 Ha (DirJen Perkebunan Indonesia, 2021). Kelapa sawit merupakan salah satu tanaman hasil perkebunan yang menghasilkan minyak nabati berupa Crude Palm Oil (CPO). Selain menghasilkan CPO, industri kelapa sawit juga menghasilkan limbah dalam jumlah yang banyak. Dalam berat 1 ton kelapa sawit dapat menghasilkan limbah seperti tandan kosong kelapa sawit sebanyak $230 \mathrm{~kg}$ atau 23\%, cangkang (shell) sebanyak $65 \mathrm{~kg}$ atau $6,5 \%$, lumpur sawit (wet decanter solid) $40 \mathrm{~kg}$ atau $4 \%$, serabut (fiber) $130 \mathrm{~kg}$ atau $13 \%$ dan 50\% limbah cair (Iswahyudi, dkk., 2017). 
Potensi peningkatan jumlah limbah yang dibuang ke lingkungan akan terus bertambah seiring dengan perkembangan perkebunan dan industri kelapa sawit yang terus meningkat. Limbah seperti cangkang dan serabut kelapa sawit biasanya dimanfaatkan oleh industri kelapa sawit untuk bahan bakar boiler. Dari pembakaran tersebut menyisakan abu sisa pembakaran yang hanya ditumpuk di sekitar area pabrik lalu dibuang ke tempat pembuangan (Zaki, dkk., 2017). Abu boiler kelapa sawit yaitu abu dari proses pembakaran cangkang dan serabut kelapa sawit dari dalam tungku pembakaran atau boiler dengan suhu $7.000{ }^{\circ} \mathrm{C}-8.000{ }^{\circ} \mathrm{C}$ (Alwi, dkk., 2020). Abu tersebut dapat digunakan sebagai salah satu bahan baku alternatif dalam pembuatan silika dikarenakan memiliki kandungan silika $\left(\mathrm{SiO}_{2}\right)$ masingmasing sebesar $61 \%$ dan 59,1\% (Balai Penelitian Tanaman Palma, 2015).

Silika gel adalah sebuah material yang memiliki stabilitas termal dan kimianya yang tinggi, selektivitas dan ketahanan yang baik, dan dapat digunakan berulang kali sehingga lebih menguntungkan secara ekonomi. Silika gel memiliki bentuk padat dan berstruktur amorf, digunakan pada industri kimia, salah satu kegunaan silika pada industri kimia adalah sebagai adsorben logam yang cukup efektif dan juga digunakan sebagai desikan pada produk makanan dan non makanan (Yuanita, 2020). Silika gel mempunyai dua situs aktif di permukaan yaitu gugus silanol $(\mathrm{Si}-\mathrm{OH})$ dan gugus siloksan ( $\mathrm{Si}-\mathrm{O}-\mathrm{Si}$ ) yang juga merupakan salah satu padatan anorganik (Sudiarta, dkk., 2013). Karena terdapat gugus -OH, gugus tersebut berpeluang luas untuk dimodifikasi menjadi gugus lainnya yang lebih aktif. Proses modifikasi dilakukan dengan mengubah gugus -Si-OH menjadi-Si-OM, di mana selain $\mathrm{H}, \mathrm{M}$ juga termasuk spesies yang sederhana ataupun kompleks. Proses adsorpsi dapat berpengaruh secara signifikan akibat proses modifikasi. Permukaan silika gel dapat dimodifikasi dengan dua metode yaitu fisik dan kimia (Nopianingsih, dkk., 2015). Terimobiliasi atau biasa disebut modifikasi artinya yaitu dilekatkan (Sumo, dkk., 1993). Tujuan modifikasi permukaan silika gel yaitu mengubah komposisi kimia pada permukaan secara keseluruhan proses.

Beberapa penelitian terdahulu tentang sintesis silika gel di antaranya, yaitu modifikasi silika gel dengan difenilkarbazon diperoleh hasil karakterisasi spektrofotometer IR di mana selain muncul serapan gugus silanol, gugus siloksan, juga juga muncul gugus $\mathrm{N}-\mathrm{H}$, gugus aromatik $\mathrm{Ar}-\mathrm{H}$, dan gugus $\mathrm{C}=\mathrm{O}$. Rasio ligan/silika gel dan waktu optimum modifikasi terjadi pada rasio ligan/silika gel $0,12 \mathrm{~g}: 0,5 \mathrm{~g}$ atau rasio 0,24 g : $1 \mathrm{~g}$ dengan waktu modifikasi 4 jam (Sudiarta, dkk., 2013). Kemudian, sintesis silika xerogel berbahan baku pasir kuarsa bangka dengan variasi konsentrasi $\mathrm{HCl}(0,5 ; 1$; dan 2) $\mathrm{M}$ dan variasi waktu pematangan gel $(12,18$, dan 24) jam. Faktor yang memengaruhi luas permukaan silika gel yaitu konsentrasi $\mathrm{HCl}$ dan waktu pemtangan gel. Diperoleh hasil optimum analisis uji luas permukaan dengan metilen biru yaitu pada $\mathrm{HCl}$ 0,5 $\mathrm{M}$ dan waktu pematangan $12 \mathrm{jam}$. Dihasilkan silika xerogel dengan luas permukaan $9,060 \mathrm{~m}^{2} \mathrm{~g}^{-1}$ (Meirawati, dkk., 2013). Modifikasi silika gel secara kimia dari abu sekam padi menggunakan Natrium Silikat $\left(\mathrm{Na}_{2} \mathrm{SiO}_{3}\right)$ sebagai prekursor, 3-kloropropiltrimetoksisilan sebagai pereaksi silan atau senyawa penghubung dan difenilkarbazon sebagai bahan modifikasi dengan proses sol-gel, dengan variasi massa difenilkarbazon $(0,05 ; 0,5$; dan 1$)$ g serta titrasi $\mathrm{HCl} 3 \mathrm{M}$, dan didapatkan hasil optimum yaitu massa difenilkarbazon 0,5 g (Nopianingsih, dkk., 2015).

Modifikasi gugus fungsi pada permukaan silika gel dapat dilakukan dengan berbagai teknik, yaitu Teknik Impregnasi (Fisik) yang dilakukan antara bahan pemodifikasi dengan permukaan padatan yang dikaitkan dengan interaksi fisik antara keduanya, baik dengan berinteraksi secara adhesif atau elektrostatik serta cara memasuki pori-pori padatan dan Teknik dengan Pembentukan Ikatan Kovalen (Kimia) yang dilakukan dengan berbagai metode, antara lain yaitu metode imobilisasi pereaksi silan dan metode sol-gel (Sulastri, dkk., 2010).

Dari beberapa metode modifikasi, metode sol-gel dipilih karena mempunyai beberapa kelebihan yaitu reaksi pengikatan berlangsung secara bersamaan dengan proses terbentuknya padatan yang menjadikan proses menjadi lebih cepat dan sederhana serta produk yang diperoleh lebih padat dan homogen. Selain itu, modifikasi lebih mudah dilakukan di laboratorium sehingga reaksi dapat dilakukan pada temperatur kamar dan menggunakan peralatan yang sederhana (Yadav, dkk., 2012). Kemudian, modifikasi diberi zat baru yaitu difenilkarbazon di mana zat tersebut adalah ligan yang bersifat polidentat yang berfungsi sebagai agen pengkelat atau chelating agent yang dalam pembentukan ikatan dengan logam berperan menyumbangkan dua atau lebih pasangan elektron bebas (Sudiarta, dkk., 2013). 
Penggumpalan berupa sol pada Natrium Silikat $\left(\mathrm{Na}_{2} \mathrm{SiO}_{3}\right)$ dapat membentuk silika gel. Pembentukan silika gel dikarenakan sol yang dihasilkan berbentuk mirip dengan agar-agar, kemudian sol akan didehidrasi hingga yang bentuk awalnya seperti agar-agar akan berubah bentuk menjadi padatan atau butiran yang mirip seperti kaca dan memiliki sifat tidak elastis. Karena memiliki sifat tersebut silika gel dapat bermanfaat sebagai zat penyerap (adsorben), pengering, dan penopang katalis (Meriatna, dkk., 2015)

Pada penelitian ini menggunakan menggunakan natrium silikat sebagai prekursor (bahan dasar), dan difenilkarbazon sebagai bahan modifikasi dengan metode sol-gel, di mana menggunakan variasi konsentrasi $\mathrm{H}_{2} \mathrm{SO}_{4}(1-5) \mathrm{M}$, variasi waktu pematangan gel (12 dan 18) jam, dan variasi massa difenilkarbazon yaitu $(0,12 \mathrm{~g}$ dan $0,18 \mathrm{~g})$. Karakterisasinya yaitu uji organoleptik, uji keasaman permukaan, uji luas permukaan dengan menentukan absorbansi zat warna metilen biru menggunakan Spektrofotometer UV-Vis, uji kadar air, dan uji daya serap terhadap uap air.

\section{METODE PENELITIAN}

\subsection{Waktu dan Tempat}

Penelitian dilakukan selama 3 (tiga) bulan yaitu periode Mei s/d Juli 2021 dan bertempat di Laboratorium Satuan Proses dan Satuan Operasi Jurusan Teknik Kimia Politeknik Negeri Sriwijaya.

\subsection{Alat dan Bahan}

Alat yang digunakan terdiri dari peralatan gelas (Iwaki Pyrex), desikator, kertas saring (Whatman No. 42), bola karet (D\&N Germany), ayakan 60 mesh dan 140 mesh, neraca analitik (Radwag AS 110/C/2), oven (Nabertherm), hotplate (Heidolph MR 3001), centrifuge (Kubota KS-8000), botol sampel, kertas $\mathrm{pH}$, mortal dan alu, cawan porselin, cawan petri, spektrofotometer UV-Vis (Agilent 8453).

Bahan baku yang dipakai pada penelitian ini yaitu Abu Cangkang dan Serabut Kelapa Sawit yang berasal dari PTPN VII Betung. Bahan lainnya antara lain Asam Klorida ( $\mathrm{HCl})$ Merck Germany (p.a), Natrium Hidroksida $(\mathrm{NaOH})$ Topaz Chemical India (p.a), Difenilkarbazon $\left(\mathrm{C}_{13} \mathrm{H}_{12} \mathrm{~N}_{4} \mathrm{O}\right)$ Merck KgaA Germany (p.a), Asam Sulfat $\left(\mathrm{H}_{2} \mathrm{SO}_{4}\right)$ Merck Germany (p.a), Toluena $\left(\mathrm{C}_{7} \mathrm{H}_{8}\right)$ Mallinckrodt Chemicals USA (p.a), Etanol $\left(\mathrm{C}_{2} \mathrm{H}_{5} \mathrm{OH}\right)$ Dira Sonita (teknis), Dietil Eter $\left(\mathrm{C}_{2} \mathrm{H}_{5}\right)_{2} \mathrm{O}$ Medical and Laboratory Supplier (teknis), Aquades, dan Indikator Fenolftalein $\left(\mathrm{C}_{20} \mathrm{H}_{14} \mathrm{O}_{4}\right)$.

\subsection{Persiapan Bahan Baku}

Sebanyak $250 \mathrm{~g}$ abu cangkang dan abu serabut kelapa sawit direndam dalam $500 \mathrm{~mL}$ larutan $\mathrm{HCl}$ $4 \mathrm{M}$ selama $3 \mathrm{jam}$, lalu dibilas dengan aquades hingga $\mathrm{pH}$ netral. Abu cangkang dan abu serabut kelapa sawit dikeringkan pada suhu $100{ }^{\circ} \mathrm{C}$ (Sudiarta, dkk., 2013).

\subsection{Sintesis Silika Gel}

Abu cangkang dan serabut kelapa sawit kering sebanyak $20 \mathrm{~g}$ ditimbang dan dicampur dengan 250 $\mathrm{mL}$ larutan $\mathrm{NaOH} 3 \mathrm{M}$. Campuran didihkan dan diaduk dengan pengaduk magnet dengan kecepatan konstan selama 1 jam. Lalu, larutan disaring menggunakan kertas saring Whatman No. 42, kemudian residu dicuci dengan $100 \mathrm{~mL}$ aquadest mendidih secara bertahap. Filtrat didinginkan dan dinetralkan dengan $\mathrm{H}_{2} \mathrm{SO}_{4}$ dengan variasi konsentrasi $(1,2,3$, 4, dan 5) $\mathrm{M}$. Gel yang terbentuk didiamkan dengan variasi waktu (12 dan 18) jam. Setelah didiamkan, disentrifugasi selama 30 menit dengan kecepatan $1500 \mathrm{rpm}$, kemudian gel dicuci dengan aquades dan disentrifugasi lagi. Selanjutnya, gel dikeringkan pada suhu $70{ }^{\circ} \mathrm{C}$ dalam oven selama 3-4 jam. Setelah kering, bubuk silika digerus dan diayak menggunakan ayakan 60 mesh dan 140 mesh. Bubuk silika yang melewati ayakan 60 mesh dan tertahan di ayakan 140 mesh disimpan dalam desikator (Sudiarta, dkk., 2013). 


\subsection{Silika Gel Terimobilisasi Difenilkarbazon}

Setelah silika gel berhasil dibuat, selanjutnya melakukan tahap imobilisasi atau modifikasi. Difenilkarbazon dimasukkan dengan variasi massa $(0,12$ dan 0,18$) \mathrm{g}$ ke dalam campuran $10 \mathrm{~mL}$ toluena dan $5 \mathrm{~mL}$ etanol, kemudian diaduk hingga larut merata. Selanjutnya, 0,5 g silika gel terimobilisasi difenilkarbazon dimasukkan ke dalam larutan sebelumnya, kemudian diaduk dengan pengaduk magnet selama 4 jam. Campuran disaring dan dicuci dengan $5 \mathrm{~mL}$ toluena, $5 \mathrm{~mL}$ etanol, dan $5 \mathrm{~mL}$ dietil eter, kemudian dikeringkan pada suhu $60{ }^{\circ} \mathrm{C}$ dalam oven. Terakhir, silika gel digerus kembali guna memperbesar luas permukaan pada silika gel (Sudiarta, dkk., 2013).

\subsection{Tahap Analisa Silika Gel}

Tahap analisis dilakukan dengan tujuan mengetahui karakterisasi silika gel terimobilisasi difenilkarbazon yang dihasilkan. Analisis yang dilakukan terhadap produk silika gel meliputi: uji organoleptik dengan metode SNI 3751:2009, uji keasaman permukaan dengan metode titrimetri (titasi asam-basa), uji luas permukaan dengan menentukan absorbansi menggunakan alat Spektrofotometer UV-Vis dengan metode daya serap zat warna metilen biru, uji kadar air dengan metode SNI 3751:2009, dan uji daya serap dengan metode penyerapan uap air dalam alat desikator.

\section{HASIL DAN PEMBAHASAN}

\subsection{Uji Organoleptik}

Pengujian organoleptik pada silika gel yang dihasilkan dari abu cangkang dan serabut kelapa sawit meliputi bentuk, warna dan bau. Silika gel yang dihasilkan pada penelitian ini berbentuk serbuk, tidak berbau, dan berwarna putih yang berarti silika ini berjenis silika xerogel (Nazriati, dkk., 2018). Silika yang dihasilkan berwarna putih, namun terjadi perubahan warna setelah dimodifikasi. Perubahan warna ini terjadi karena adanya penambahan zat modifikasi yaitu difenilkarbazon $\left(\mathrm{C}_{13} \mathrm{H}_{12} \mathrm{~N}_{4} \mathrm{O}\right)$ yang berwarna oranye. Difenilkarbazon dilarutkan dalam pelarut campuran toluena dan etanol yang mengakibatkan larutan berwarna kemerahan, kemudian disaring hingga didapatkan Si-DPZon berwarna putih dan sedikit kepinkan yang dapat dilihat pada Gambar 1.

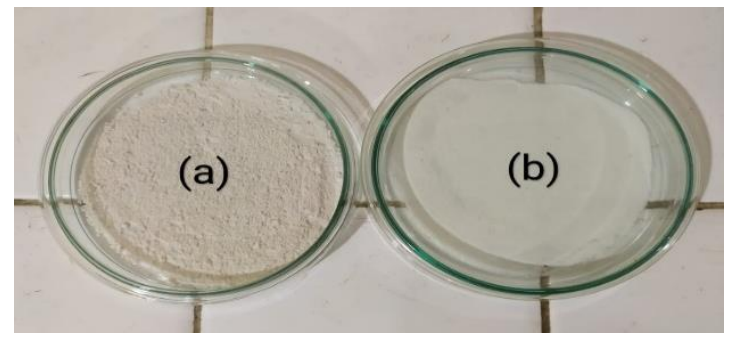

Gambar 1. (a) Silika Gel Setelah Modifikasi; (b) Silika Gel Sebelum Modifikasi

Berdasarkan Gambar 1(a) dan 1(b), terlihat adanya perubahan warna menjadi putih kepinkan setelah ditambahkan zat difenilkarbazon yang menandakan bahwa proses modifikasi pada silika gel berhasil dilakukan yang artinya zat difenilkarbazon terlekatkan pada silika gel. Setelah dimodifikasi, terjadi penambahan gugus fungsi lainnya seperti gugus $(\mathrm{N}-\mathrm{H})$, gugus karbonil $(\mathrm{C}=\mathrm{O})$, dan senyawa aromatik (Ar-H) (Sudiarta, dkk., 2013).

\subsection{Uji Keasaman Permukaan}

Nilai keasaman permukaan pada adsorben digunakan untuk mengetahui jumlah mmol situs asam yang terikat pada adsorben tiap gramnya. Uji keasaman permukaan dilakukan secara kuantitatif menggunakan metode titrimetri (titrasi asam-basa), di mana situs asam adsorben direaksikan dengan basa $(\mathrm{NaOH})$ berlebih (Wogo, dkk., 2014). Hasil analisis keasaman permukaan dapat dilihat pada Gambar 2 dan Gambar 3. 


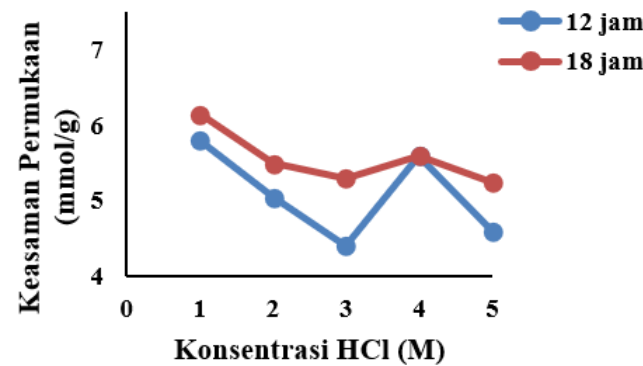

Gambar 2. Pengaruh Konsentrasi $\mathrm{H}_{2} \mathrm{SO}_{4}$ terhadap Keasaman Permukaan Variasi Difenilkarbazon $0,12 \mathrm{~g}$

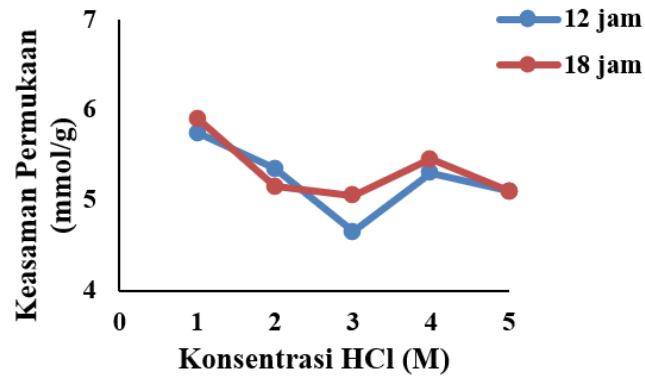

Gambar 3. Pengaruh Konsentrasi $\mathrm{H}_{2} \mathrm{SO}_{4}$ terhadap Keasaman Permukaan Variasi Difenilkarbazon 0,18 g

Berdasarkan Gambar 2, didapatkan nilai keasaman permukaan terbaik yaitu $6,15 \mathrm{mmol} / \mathrm{g}$ dengan konsentrasi $\mathrm{H}_{2} \mathrm{SO}_{4} 1 \mathrm{M}$, waktu pematangan gel 18 jam, dan massa difenilkarbazon 0,12 g. Pada Gambar 3 , didapatkan nilai keasaman permukaan terbaik yaitu $5,90 \mathrm{mmol} / \mathrm{g}$ dengan konsentrasi $\mathrm{H}_{2} \mathrm{SO}_{4} 1 \mathrm{M}$, waktu pematangan $18 \mathrm{jam}$, dan massa difenilkarbazon $0,18 \mathrm{~g}$. Keasaman permukaan pada silika gel terimobilisasi difenilkarbazon dipengaruhi oleh faktor keberadaan situs aktif berupa gugus silanol (-OH) pada silika gel, gugus karbonil $(\mathrm{C}=\mathrm{O})$ dan senyawa aromatik yang terdapat pada difenilkarbazon (Giri, dkk., 2014).

\subsection{Uji Luas Permukaan}

Luas permukaan adsorben merupakan salah satu karakter fisik yang penting dalam proses adsorpsi karena banyaknya jumlah zat tiap gramnya yang teradsorpsi. Pada penelitian ini luas permukaan ditentukan dengan metode penyerapan zat warna metilen biru, penyerapan metilen biru sebanding dengan luas permukaan adsorben (Giri, dkk., 2014). Dengan banyaknya adsorbat yang terkumpul di permukaan adsorben maka akan diperoleh adsorben yang memiliki kapasitas adsorpsi yang maksimum pada kondisi optimum saat proses adsorpsi berlangsung (Aisyahlika, dkk., 2018). Hasil analisis luas permukaan dapat dilihat pada Gambar 4 dan Gambar 5.

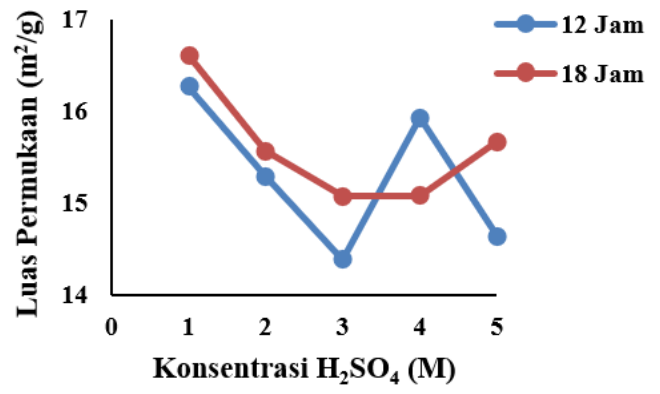

Gambar 4. Pengaruh Konsentrasi $\mathrm{H}_{2} \mathrm{SO}_{4}$ terhadap Luas Permukaan Variasi Difenilkarbazon 0,12 g 


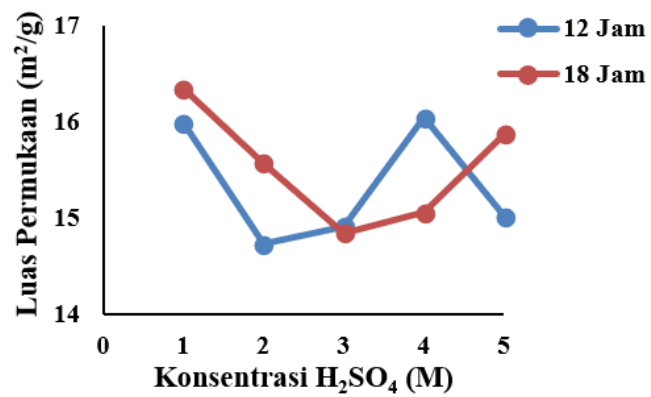

Gambar 5. Pengaruh Konsentrasi $\mathrm{H}_{2} \mathrm{SO}_{4}$ terhadap Luas Permukaan Variasi Difenilkarbazon 0,18 g

Berdasarkan Gambar 4, didapatkan nilai luas permukaan terbaik, yaitu $16,62 \mathrm{~m}^{2} / \mathrm{g}$ pada variasi konsentrasi $\mathrm{H}_{2} \mathrm{SO}_{4} 1 \mathrm{M}$ dan waktu pematangan gel 18 jam. Pada Gambar 5, didapatkan nilai luas permukaan terbaik, yaitu $16,35 \mathrm{~m}^{2} / \mathrm{g}$ pada variasi konsentrasi $\mathrm{H}_{2} \mathrm{SO}_{4} 1 \mathrm{M}$ dan waktu pematangan gel 18 jam. Faktor yang memengaruhi luas permukaan silika gel yaitu waktu pematangan gel. Nilai luas permukaan akan semakin besar disebabkan lamanya waktu pematangan gel, karena adanya kekuatan ikatan jaringan silika gel yang semakin kuat. Selain itu, oleh faktor penggerusan dan pengayakan yang dilakukan pada silika gel, di mana hal tersebut dapat memperkecil dan menghomogenkan ukuran partikel serta memperbesar luas permukaan partikel silika gel (Nopianingsih, dkk., 2015). Ukuran partikel menjadi faktor penentu tingginya kapasitas adsorpsi suatu absorben (Reyra, dkk., 2017). Luas permukaan adsorben berbanding terbalik dengan ukuran partikel yang terikat pada adsorben. Semakin besar luas permukaan pada adsorben maka ukuran partikel adsorben semakin kecil (Giri, dkk., 2014).

\subsection{Uji Kadar Air}

Penentuan kadar air silika gel dilakukan untuk mengetahui jumlah air yang dilepaskan oleh silika gel selama pemanasan pada temperatur tertentu. Pengujian kadar air bertujuan untuk mengetahui persentase kandungan air dalam produk yang dihasilkan, agar dapat mengoptimalkan dalam penyerapan uap air. Kadar air dalam hal ini diartikan sebagai banyaknya air yang dilepaskan oleh silika gel akibat pemanasan pada temperatur $130^{\circ} \mathrm{C}$ selama 1 jam. Nilai $\%$ kadar air dapat dihitung dengan mengurangi berat sampel awal dengan berat sampel setelah pemanasan (SNI 3751-2009). Hasil dari analisis kadar air dapat dilihat pada Gambar 6 dan Gambar 7.

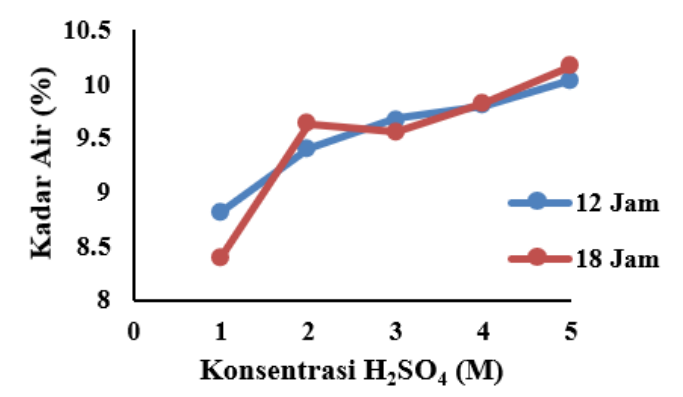

Gambar 6. Grafik Pengaruh Konsentrasi $\mathrm{H}_{2} \mathrm{SO}_{4}$ terhadap Kadar Air Variasi Difenilkarbazon 0,12 g

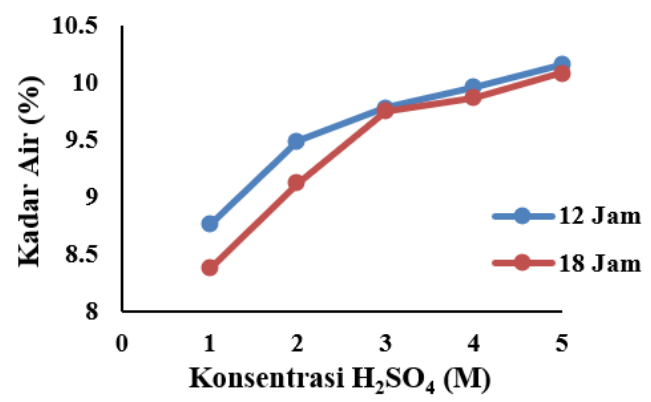

Gambar 7. Grafik Pengaruh Konsentrasi $\mathrm{H}_{2} \mathrm{SO}_{4}$ terhadap Kadar AirVariasi Difenilkarazon 0,18 g 
Berdasarkan Gambar 6, didapatkan \% kadar air terendah yaitu 8,40\% dengan konsentrasi $\mathrm{H}_{2} \mathrm{SO}_{4} 1$ M, waktu pematangan gel 18 jam, dan massa difenilkarbazon 0,12 g. Pada Gambar 7, \% kadar air terendah yaitu 8,38\% dengan konsentrasi $\mathrm{H}_{2} \mathrm{SO}_{4} 1 \mathrm{M}$, waktu pematangan gel 18 jam, dan massa difenilkarazon 0,18 g. Faktor yang memengaruhi \% kadar air yaitu konsentrasi asam. Pengaruh konsentrasi asam berbanding lurus dengan \% kadar air yang dihasilkan. Jika konsentrasi asam $\left(\mathrm{H}_{2} \mathrm{SO}_{4}\right)$ yang digunakan semakin tinggi maka kadar air yang terkandung pada silika gel juga menjadi lebih tinggi. Hal ini dikarenakan semakin tinggi konsentrasi asam yang diberikan maka jumlah proton yang terkandung dalam larutan akan bertambah sehingga gugus silanol akan meningkat dan memengaruhi kadar air silika (Meidinariasty, dkk., 2020). Faktor lain yang berpengaruh terhadap kadar air silika yaitu jumlah uap air di udara dan efisiensi waktu saat proses pemanasan (Hidayat, dkk., 2016).

\subsection{Uji Daya Serap}

Pengujian daya serap dilakukan dengan tujuan untuk mengetahui kemampuan absorben dalam menyerap uap air pada silika. Hasil dari pengujian daya serap pada silika gel berdasarkan konsentrasi $\mathrm{H}_{2} \mathrm{SO}_{4}$ dapat dilihat pada Gambar 8 dan Gambar 9.

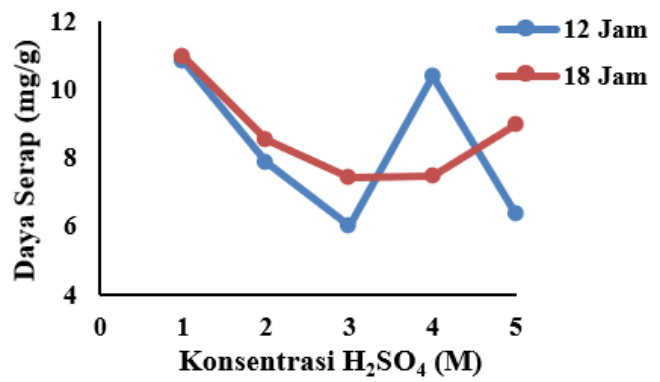

Gambar 8. Grafik Pengaruh Konsentrasi $\mathrm{H}_{2} \mathrm{SO}_{4}$ terhadap Daya Serap Variasi Difenilkarbazon 0,12 g

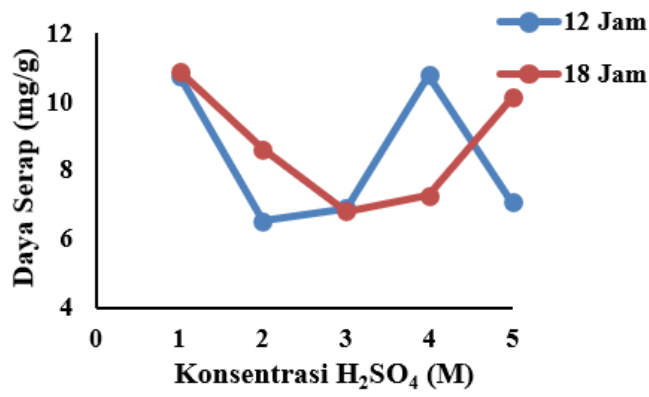

Gambar 9. Grafik Pengaruh Konsentrasi $\mathrm{H}_{2} \mathrm{SO}_{4}$ terhadap Daya Serap Variasi Difenilkarbazon 0,18 g

Berdasarkan Gambar 8, didapatkan hasil kemampuan daya serap silika gel terhadap uap air dengan nilai tertinggi, yaitu $10,96 \mathrm{mg} / \mathrm{g}$ dengan konsentrasi $\mathrm{H}_{2} \mathrm{SO}_{4} 1 \mathrm{M}$, waktu pematangan gel $18 \mathrm{jam}$, dan massa difenilkarbazon 0,12 g. Kemudian, pada Gambar 9, kemampuan daya serap silika gel tertinggi yaitu $10,88 \mathrm{mg} / \mathrm{g}$. Faktor yang memengaruhi nilai daya serap yaitu waktu pematagan gel, di mana semakin lama waktu pematangan gel maka kemampuan daya serap silika gel semakin tinggi, karena adanya kekuatan ikatan jaringan silika gel yang semakin kuat. Faktor lain yaitu konsentrasi $\mathrm{H}_{2} \mathrm{SO}_{4}$, di mana pada konsentrasi $\mathrm{H}_{2} \mathrm{SO}_{4} 3 \mathrm{M}$ daya serap yang dihasilkan sangat rendah, silika gel yang diperoleh mudah hancur dan menyebabkan berkurangnya daya serap uap air pada silika gel (Yuanita, 2020). Nilai daya serap sampel sesudah modifikasi lebih tinggi daripada sebelum modifikasi dikarenakan adanya tambahan gugus fungsi lainnya yang berasal dari difenilkarbazon, seperti gugus $(\mathrm{N}-\mathrm{H})$, gugus karbonil $(\mathrm{C}=\mathrm{O})$, dan senyawa aromatik (Ar-H) (Sudiarta, dkk., 2013). 


\subsection{Hasil Penelitian Secara Keseluruhan dan Interpretasi}

Berdasarkan penelitian yang telah dilakukan, didapatkan hasil penelitian secara keseluruhan sebagai berikut yaitu hasil uji organoleptik pada silika gel silika gel yang dihasilkan yaitu berbentuk serbuk, tidak berbau, dan berwarna putih yang berarti silika ini berjenis silika xerogel yang kemudian terjadi perubahan warna menjadi putih kepinkan setelah dimodifikasi zat difenilkarbazon. Hasil uji keasaman permukaan terbaik yaitu $6,15 \mathrm{mmol} / \mathrm{g}$ dengan konsentrasi $\mathrm{H}_{2} \mathrm{SO}_{4} 1 \mathrm{M}$, waktu pematangan gel $18 \mathrm{jam}$, dan massa difenilkarbazon $0,12 \mathrm{~g}$. Hasil uji luas permukaan terbaik yaitu $16,62 \mathrm{~m}^{2} / \mathrm{g}$ pada variasi konsentrasi $\mathrm{H}_{2} \mathrm{SO}_{4} 1 \mathrm{M}$, waktu pematangan gel $18 \mathrm{jam}$, dan massa difenilkarbazon 0,12 g. Hasil uji kadar air terendah yaitu $8,38 \%$ pada variasi konsentrasi $\mathrm{H}_{2} \mathrm{SO}_{4} 1 \mathrm{M}$, waktu pematangan gel $18 \mathrm{jam}$, dan massa difenilkarbazon $0,18 \mathrm{~g}$. Hasil uji kemampuan daya serap silika gel terhadap uap air dengan nilai tertinggi, yaitu $10,96 \mathrm{mg} / \mathrm{g}$ dengan konsentrasi $\mathrm{H}_{2} \mathrm{SO}_{4} 1 \mathrm{M}$, waktu pematangan gel $18 \mathrm{jam}$, dan massa difenilkarbazon $0,12 \mathrm{~g}$.

Berdasarkan penelitian yang dilakukan, maka penulis dapat memberikan interpretasi terhadap hasil penelitian sebagai berikut, yaitu bahwa sintesis silika gel menggunakan bahan baku abu cangkang dan serabut kelapa sawit dengan metode sol-gel akan menghasilkan silika jenis xerogel (bubuk) yang kemudian dimodifikasi dengan penambahan zat difenilkarbazon sehingga menghasilkan produk dengan fungsi yang lebih baik dengan spesifikasi luas permukaan yang lebih besar dan persen kadar air yang lebih rendah sehingga penyerapan uap air dapat dilakukan oleh absorben dengan lebih optimal dikarenakan adanya penambahan gugus fungsi lain, seperti gugus $(\mathrm{N}-\mathrm{H})$, gugus karbonil $(\mathrm{C}=\mathrm{O})$, dan senyawa aromatik $(\mathrm{Ar}-\mathrm{H})$.

\section{KESIMPULAN}

Berdasarkan penelitian yang telah dilakukan, maka dapat disimpulkan sebagai berikut:

a. Konsentrasi $\mathrm{H}_{2} \mathrm{SO}_{4}$ berpengaruh terhadap nilai \% kadar air, di mana \% kadar air silika gel akan tinggi, jika konsentrasi asam $\left(\mathrm{H}_{2} \mathrm{SO}_{4}\right)$ yang digunakan dalam sintesis silika gel juga semakin tinggi. $\%$ Kadar air terendah yaitu 8,38\% dengan konsentrasi $\mathrm{H}_{2} \mathrm{SO}_{4} 1 \mathrm{M}$, waktu pematangan gel 18 jam, dan massa difenilkarazon $0,18 \mathrm{~g}$.

b. Waktu pematangan gel berpengaruh terhadap nilai luas permukaan dan daya serap. Luas permukaan terbaik yaitu $16,62 \mathrm{~m}^{2} / \mathrm{g}$ pada konsentrasi $\mathrm{H}_{2} \mathrm{SO}_{4} 1 \mathrm{M}$ dan waktu pematangan gel 18 jam. Daya serap silika gel terhadap uap air dengan nilai tertinggi yaitu $10,96 \mathrm{mg} / \mathrm{g}$ dengan konsentrasi $\mathrm{H}_{2} \mathrm{SO}_{4} 1 \mathrm{M}$, waktu pematangan gel $18 \mathrm{jam}$, dan massa difenilkarbazon $0,12 \mathrm{~g}$.

c. Massa difenilkarbazon berpengaruh terhadap hasil analisa organoleptik di mana terdapat perbedaan warna setelah dimodifikasi yang menjadi warna putih kepinkan dikarenakan penambahan zat difenilkarbazon yang berwarna oranye sehingga dihasilkan silika gel dengan karakterisasi yang lebih optimum.

\section{DAFTAR PUSTAKA}

Aisyahlika, Siti Zaya, M. Lutfi Firdaus, dan Rina Elvia. (2018). Kapasitas Adsorpsi Arang Aktif Cangkang Bintaro (Cerbera odollam) Terhadap Zat Warna Sintetis Reactive Red-120 dan Reactive Blue-198. Jurnal Pendidikan dan Ilmu Kimia, 2(2), 148-155.

Alwi, Salma, Ashadi Putrawirawan, dan Rahmat Hidayat. (2020). Pengaruh Penggunaan Abu Cangkang Kelapa Sawit Sebagai Filler Terhadap Karakteristik Marshall pada Campuran Asphalt Concrete Binder Course (AC-BC). Jurnal Inersia, 12(2), 17-24.

Balai Penelitian Tanaman Palma. (2015). Pemanfaatan Cangkang dan Sabut Kelapa Sawit Sebagai Sumber Silika Alternatif. Manado: Kementerian Pertanian RI.

DirJen Perkebunan Indonesia. (2021). Luas Areal Kelapa Sawit Menurut Provinsi di Indonesia, 20172021. Jakarta: Kementerian Pertanian RI.

Giri, Henny Puspa Dewi, I Wayan Sudiarta, dan Ida Ayu Raka Astiti Asih. (2014). Optimasi Adsorpsi Cr (VI) Pada Silika Gel dari Abu Sekam Padi Termodifikasi Difenilkarbazida (Si-DPZida). Jurnal Kimia, 8(2), 198-204. 
Hidayat, Muhammad Iqbal Fitrah dan Mitarlis. (2016). Karakteristik Silika dari Limbah Padat Hasil Sintesis Furfural Berbahan Dasar Sekam Padi. UNESA Journal of Chemistry, 5(2), 108-115.

Meidinariasty, Anerasari, Indah Purnamasari, Mustain Zamhari, Jekasyah Permadi, Nadia Zaky Fadillah, Sakinah Luthfiah, dan Fadarina. (2020). Pengaruh Variasi Jenis Abu Boiler dan Kosentrasi HCl Terhadap Sifat Fisis Silika Gel Hasil Sintesis. Jurnal Kinetika, 11(03), 28-33.

Meirawati, Dian, Sri Wardhani, dan Rachmat Triandi Tjahjanto. (2013). Studi Pengaruh Konsentrasi $\mathrm{HCl}$ dan Waktu Aging (Pemantangan Gel) Terhadap Sintesis Silika Xerogel Berbahan Dasar Pasir Kuarsa Bangka. KIMIA STUDENT JOURNAL, 2(2), 524-531.

Meriatna, Leni Maulinda, Munawar Khalil, dan Zulmiardi. (2015). Pengaruh Temperatur Pengeringan dan Konsentrasi Asam Sitrat pada Pembuatan Silika Gel dari Sekam Padi. Jurnal Teknologi Kimia Unimal, 4(1), 78-88.

Nazriati, Tatiana Samantha Putri, Agus Jalaluddin, Fauziatul Fajaroh, dan Sumari. (2018). Efek Kondisi Aging terhadap Karakteristik Silika Xerogel. Prosiding Seminar Nasional Kimia dan Pembelajarannya (SNKP), 176-181.

Nopianingsih, N.N.S., I Wayan Sudiarta, dan Wahyu Dwijani Sulihingtyas. (2015). Sintesis Silika Gel Terimobilisasi Difenilkarbazon dari Abu Sekam Padi Melalui Teknik Sol Gel. Jurnal Kimia, 9(2), 226-234.

Reyra, Silvi Anilza, Syarfi Daud, dan Silvia Reni Yenti. (2017). Pengaruh Massa dan Ukuran Partikel Adsorben Daun Nanas Terhadap Efisiensi Penyisihan Fe pada Air Gambut. Jom FTEKNIK, 4(2), $1-9$.

Standar Nasional Indonesia. (2009). Tepung Terigu Sebagai Bahan Makanan (SNI 3751-2009). Standar Nasional Indonesia.

Sudiarta, I Wayan, Ni Putu Diantariani, dan Putu Suarya. (2013). Modifikasi Silika Gel dari Abu Sekam Padi dengan Ligan Difenilkarbazon. Jurnal Kimia, 7(1), 57-63.

Sulastri, Siti dan Susila Kristianingrum. (2010). Berbagai Macam Senyawa Silika: Sintesis, Karakterisasi dan Pemanfaatan. Prosiding Seminar Nasional Penelitian, Pendidikan dan Penerapan MIPA, 211-216.

Sumo, Usman F., Bambang Sumantri, dan Agung Subono. (1993). Prinsip Bioteknologi. Jakarta, Indonesia: PT Gramedia Pustaka Utama, 1-202.

Wogo, Hermania Em, Luther Kadang, dan Magdalena A. Mir. (2014). Termodinamika Adsorpsi Ca (II) dan Cd (II) pada Adsorben Ampas Tahu. Sains dan Terapan Kimia, 8(2), 120-128.

Yadav, P dan M.C. Bhatnagar. (2012). Structural Studies of NASICON Material of Different Composition by Sol-Gel Method. Ceramics International 38, 1731-1735.

Yuanita, Trisna Putri. (2020). Pengaruh Konsentrasi Pelarut dan Waktu Aging Pada Pembuatan Silika Gel dari Abu Terbang (Fly Ash) Batu Bara. Departemen Teknik Kimia. Fakultas Teknik. Universitas Sumatera Utara.

Zaki, Ahmad, Edy Saputra, dan Ahmad Fadli. (2017). Pembuatan Silika High Grade dari Fly Ash Sawit dengan Proses Ekstraksi dan Cation Exchange. Jom FTEKNIK, 4(2), 1-4. 


\section{Halaman Ini Dikosongkan}

